\title{
Lusioersily
}

\section{Modelling and experimental evaluation of an innovative Integrated Collector Storage Solar Water Heating (ICSSWH) prototype}

Smyth, M., Barone, G., Buonomano, A., Forzano, C., Giuzio, G. F., Palombo, A., Mondol, J., Muhumuza, R., Pugsley, A., Zacharopoulos, A., \& McLarnon, D. (2020). Modelling and experimental evaluation of an innovative Integrated Collector Storage Solar Water Heating (ICSSWH) prototype. Renewable Energy, 157, $974-986$. https://doi.org/10.1016/j.renene.2020.05.074

Link to publication record in Ulster University Research Portal

\section{Published in:}

Renewable Energy

Publication Status:

Published (in print/issue): 01/09/2020

DOI:

10.1016/j.renene.2020.05.074

\section{Document Version}

Author Accepted version

\section{General rights}

Copyright for the publications made accessible via Ulster University's Research Portal is retained by the author(s) and / or other copyright owners and it is a condition of accessing these publications that users recognise and abide by the legal requirements associated with these rights.

\section{Take down policy}

The Research Portal is Ulster University's institutional repository that provides access to Ulster's research outputs. Every effort has been made to ensure that content in the Research Portal does not infringe any person's rights, or applicable UK laws. If you discover content in the Research Portal that you believe breaches copyright or violates any law, please contact pure-support@ulster.ac.uk. 


\title{
Modelling and experimental evaluation of an innovative Integrated Collector Storage Solar Water Heating (ICSSWH) prototype
}

\author{
Mervyn Smyth ${ }^{\mathrm{a}, *}$, Giovanni Barone ${ }^{\mathrm{b}}$, Annamaria Buonomano ${ }^{\mathrm{b}, \mathrm{c}}$, Cesare Forzano ${ }^{\mathrm{d}}$, \\ Giovanni Francesco Giuzio ${ }^{\mathrm{b}}$, Adolfo Palombo ${ }^{\mathrm{b}}$, Jayanta Mondol ${ }^{\mathrm{a}}$, Ronald Muhumuza ${ }^{\mathrm{a}}$, Adrian Pugsley ${ }^{\mathrm{a}}$, Aggelos \\ Zacharopoulos $^{\mathrm{a}}$, Dominic McLarnon ${ }^{\mathrm{a}}$

\footnotetext{
${ }^{\text {a }}$ School of Architecture and the Built Environment, Ulster University, Newtownabbey, Northern Ireland, UK

${ }^{\mathrm{b}}$ Department of Industrial Engineering, University of Naples Federico II, Naples, Italy

${ }^{\mathrm{c}}$ Department of Building, Civil and Environmental Engineering, Concordia University, Montreal, Canada

${ }^{\mathrm{d}}$ Faculty of Science and Technology, Free University of Bozen-Bolzano, Bozen-Bolzano, Italy
}

\begin{abstract}
An advanced mathematical model capable of simulating the energy performance of an innovative Integrated Collector Storage Solar Water Heater (ICSSWHs) is presented. Usually, ICSSWH devices available in the market are typically simple and low-cost, combining solar heat collection and storage functions in one unified vessel. However, they exhibit higher heat loss characteristics when compared to standard solar collector systems, with a subsequent reduction in energy performance during night-time and non-collecting hours. An innovative ICSSWH prototype was developed at the Centre for Sustainable Technologies (CST) at Ulster University using a patented, innovative thermal diode feature, attained by incorporating a liquid-vapour phase change material (PCM) and very low pressures. In order to fully investigate the energy performance of the proposed prototype, a suitably dynamic simulation model has been developed and validated in MatLab environment. All modelled temperatures are $\pm 1^{\circ} \mathrm{C}$ from the respective experimental measurements. The developed model has been used to evaluate the ICSSWH energy performance by varying several pivotal parameters (physical features and materials) in order to produce an optimized device.
\end{abstract}

\section{KEYWORDS}

Solar thermal collector, ICSSWH, dynamic simulation model, thermal diode 


\section{Introduction}

Integrated Collector Storage Solar Water Heaters (ICSSWH) combine solar collection and thermal storage in a simple and low-cost device. The first ICSSWH systems consisted of blackened water tanks, exposed to the sun to allow heat collection. They were employed in rural areas, mostly located in the South-West of the USA (in farms and ranches) in the late 1800s, with the aim of producing hot water for showering needs [1]. Since these early units, ICSSWHs have developed significantly and their potential to extend modern small-scale solar hot water systems for dwellings (single and multi-family) is apparent. In this regard, to boost the interest of the global solar heating market, simple, reliable and low-cost configurations are being developed.

In the available literature, the development of ICSSWH systems have been described in detail in many studies, demonstrating that significant enhancement of their thermal performance can be obtained by reducing heat losses from the storage element [2]. In this regard, ambient heat loss occurring, specifically during night-time and non-collection periods, is considered the main issue with this technology and storage heat retention represents its weakest component, as reported by Smyth et al. [3] and, more recently, by Singh et al [4]. The Integrated Collector Storage (ICS) tanks can have different shapes, from simple cylindrical [5] and rectangular [6] to triangular [7] and trapezoidal [8], each with a different impact on the system efficiency depending on the surface to volume ratio (i.e. the lower the higher the system efficiency).

In order to enhance the thermal efficiency of ICSSWH systems, different techniques have been developed. Chaurasia and Twidell [9] presented work on the reduction of aperture heat losses for devices with a large exposure surface (i.e. high surface to volume ratio), based on the substitution of the air layer underneath the glazing with a transparent insulation material, achieving a significant reduction of losses. The same goal is obtained by Kaushik et al. [7]. By subdividing the ICS tank into two parts by means of an insulating baffle, the unit was able to cut thermal losses during the night. In the case of low surface to volume ratio units, an increase in thermal efficiency is achieved by enhancing the collection of solar irradiation through the use of reflectors. Different symmetric and asymmetric Compound Parabolic Concentrators (CPC) geometries were considered in ICSSWHs to enhance the system performance during both solar energy collection and cool-down periods. Tripanagnostopoulos and Yanoulis [10] designed and tested a horizontal cylindrical tank ICSSWH system placed in a curved asymmetric mirror envelope (determining the proper shape by taking into account elements of previous studies on symmetric Compound Parabolic Concentrator 
(CPC) and asymmetric concentrators [11]), developed to minimize thermal losses from the absorber by keeping a sufficient temperature level during the night. A symmetrical CPC was used by Kalogirou [5] to develop an ICSSWH device with a horizontal cylindrical tank, whereas Tripanagnostopoulos and Souliotis [12] and Souliotis et al. [13] investigated the use of CPC in horizontal and vertical, as well as inclined, cylindrical water storage tanks. The study of the energy performance of novel configuration of an inverted absorber ICSSWH fixed in a CPC cavity was presented by Smyth et al. [14]. Muhumuza et al [15] report the use of a novel ICSSWH mounted within an asymmetric formed reflector that was specifically designed to the ICS tank requirements, giving rise to the Asymmetric Formed Reflector with Integrated Collector and Storage (AFRICaS) system. To increase heat retention, Souliotis et al. [16, 17] incorporated an ICSSWH within an asymmetric CPC using a novel ICS tank configuration consisting of two concentric cylindrical vessels. This double vessel, thermal diode transfer mechanism was first reported by De Beijer's [18]. Souliotis et al. [16] thermally tested the system but also conducted a detailed optical analysis of the novel heat retaining ICS vessel device through ray tracing and experimentation.

In order to improve the state-of-the-art on the ICSSWH research, in previously published works $[19,20,21]$, an innovative device named SolaCatcher [22] has been developed, fabricated and tested at the Centre for Sustainable Technologies (CST) at Ulster University. Specifically, the device uses a novel thermal diode feature, developed to enhance heat retention during cool-down periods, which represents a great innovation in the ICSSWH research field. The system comprises a liquid-vapour phase change material (PCM) within a double tank arrangement and very low annulus pressures (however, also other geometries were previously investigated, including horizontal planar Liquid-Vapour Thermal Diode (PLVTD) units [23]).

In order to boost the proposed ICSSWH prototype enhancement, this paper presents an advanced mathematical model capable of simulating dynamically the SolaCatcher energy performance. The developed model is capable of predicting the device performance by taking into account complex heat transfer phenomena connected to the PCM evaporation and condensation processes. The innovative mathematical tool is also validated through an experimental program carried out in the solar simulation test facility at the CST. Specifically, all the modelled temperatures are $\pm 1^{\circ} \mathrm{C}$ from the respective experimental measurements, with corresponding average percentage errors ranging from $0.92 \%$ to $1.64 \%$ for the main collector surfaces temperatures, proving the simulation tool accuracy. By adopting the validated tool, a prototype comparison is performed in order to prove the proposed device convenience over other systems with similar geometry but without the innovative 
thermal diode feature. From the carried-out comparison, the ICSSWHs prototype is characterized by higher temperatures ( 4 and $7{ }^{\circ} \mathrm{C}$ after $6 \mathrm{hrs}$ collection and $18 \mathrm{hrs}$ retention) versus simpler collector typologies, thus proving its benefit. By means of the developed model it will be also possible, in future works, to optimize the device's energy performance by varying several pivotal parameters (physical features and materials) in order to fabricate a fully optimize device.

To the best of authors' knowledge, the development of a dynamic simulation model for such solar prototypes along with the experimental model validation represents a remarkable advancement in this research area including clear literature novelty.

\section{Collector description}

The SolaCatcher is a promising ICSSWH that offers improved heat retention through the convection suppression transparent covering and a novel thermal diode design [22]. The "thermal diode" is a technology that has been developed to maximize solar heat collection and transfer to the water stored in the tank whilst minimising heat losses during cool-down periods. A small volume of liquid-vapour phase change material (PCM) (or heat transfer fluid (HTF)) within the evacuated annulus of the concentric cylindrical vessels controls the forward and reverse working condition of the proposed device, as shown in Figure 1.

During the forward working condition, the PCM evaporates in the annulus as solar radiation heats the absorber (evaporator) surface. The vapour then condenses on the outer surface of the inner storage tank (condenser), releasing latent heat of vaporisation to the storage before returning to the sump as liquid. In the reverse mode of operation, the very low pressure in the annulus (along with the transparent outer casing) minimises convective and radiative losses to ambient. The existence of non-condensable gases in the cavity of the thermal diode can significantly weaken the forward mode heat transfer rate [24, 25]. Achieving the lowest cavity pressure possible improves the effective forward mode heat transfer; however, in practice, the cavity volume, gas load and capacity of the vacuum pump govern the minimum achievable cavity pressure. The gas load depends upon the PCM vapour and dissolved non-condensable gases released from the reservoir, which provides the PCM used in wetting the evaporator. 

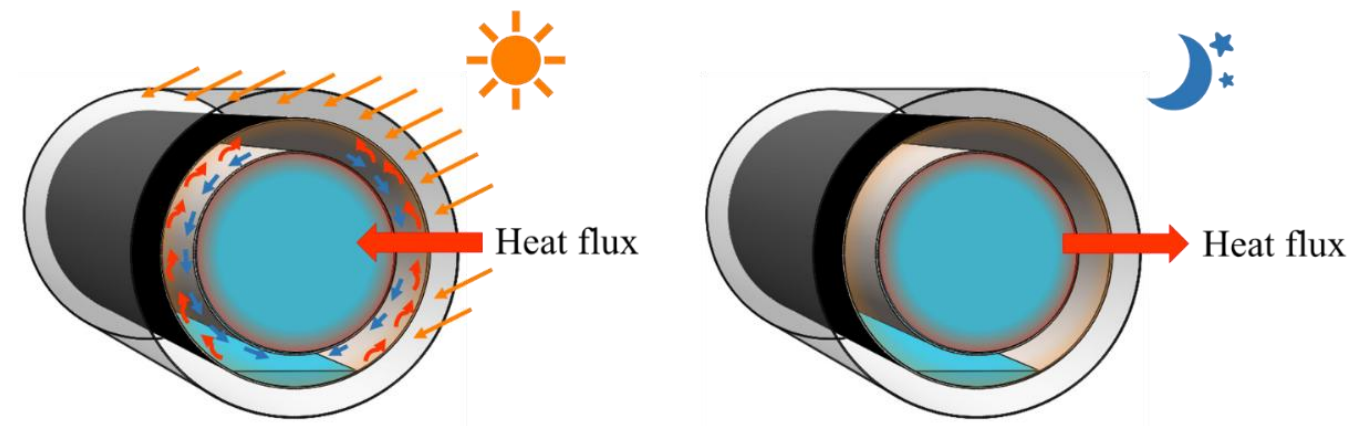

Figure 1. SolaCatcher operating principles: forward mode (left); reverse mode (right).

Smyth et al $[19,20]$ determined the thermal performance of vertically operating thermal diode prototypes of the SolaCatcher, by means of measurements, obtaining 6 hour collection and 18 hour thermal retention efficiencies equal to $36 \%$ and $60 \%$, respectively. Experimental results suggested that the vertical installation is preferable for a better thermal stratification within the storage tank, which is beneficial in cold/temperate climate conditions in northern European regions [26]. Horizontally mounted units, however, could be just as good when operating in regions with significant solar irradiation levels. Figure 2 depicts a horizontally mounted SolaCatcher prototype installed and operating in Northern Botswana. The main geometrical and thermal features of the ICSSWH prototype presented are detailed in Table 1.

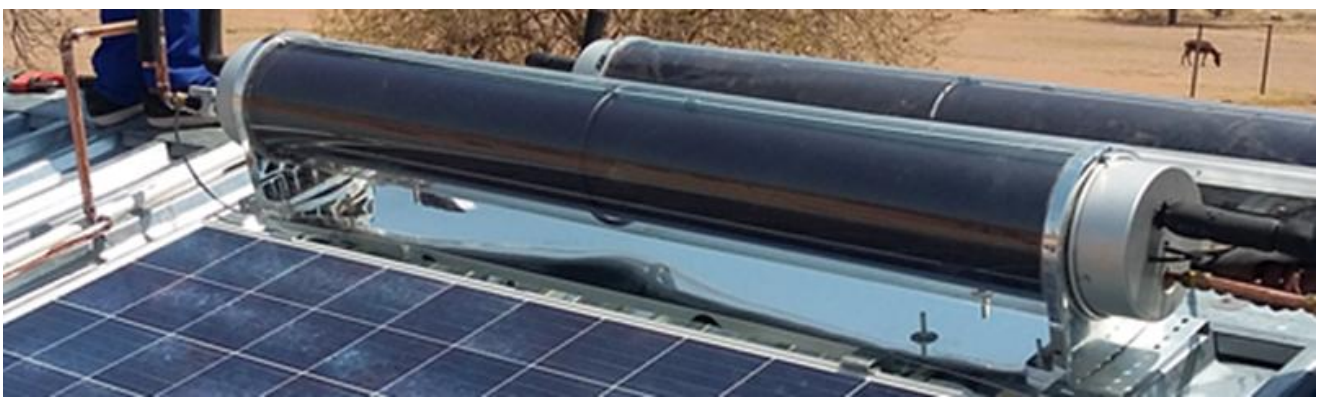

Figure 2. Installed horizontal SolaCatcher prototype in Northern Botswana.

Table 1. Main features of the investigated SolaCatcher prototype.

\begin{tabular}{|c|c|c|c|c|c|c|c|}
\hline \multirow[t]{2}{*}{ Element } & \multirow[t]{2}{*}{ Material } & Length & $\begin{array}{l}\text { External } \\
\text { diameter }\end{array}$ & Thickness & $\begin{array}{c}\text { Thermal } \\
\text { conductivity }\end{array}$ & $\tau \alpha$ & $\varepsilon$ \\
\hline & & {$[\mathrm{m}]$} & [m] & {$[\mathrm{mm}]$} & {$[\mathrm{W} / \mathrm{mK}]$} & {$[-]$} & {$[-]$} \\
\hline Glass cover & $\begin{array}{l}\text { PETG } \\
\end{array}$ & 1.65 & 0.24 & $\overline{1}$ & 0.25 & 0.75 & 0.85 \\
\hline Outside cylinder & Stainless steel & 1.65 & 0.20 & 1.5 & 16 & - & 0.9 \\
\hline \multirow{2}{*}{ Inside cylinder } & Stainless steel & 1.65 & 0.15 & 1.5 & 16 & - & 0.9 \\
\hline & $\mathrm{PVC}$ & 0.12 & 0.17 & 20 & 0.18 & - & 0.85 \\
\hline
\end{tabular}

\section{SolaCatcher Mathematical model}

A suitable mathematical model was purposely developed (and implemented in MatLab 
environment) for dynamically simulating the energy performance of the collector by varying the related boundary conditions. For the sake of simplicity, the SolaCatcher temperatures are assessed by considering the following assumptions:

- Cylindrical surfaces are assumed as isothermal (1D model);

- Heat losses through the thermally insulated bases are neglected;

- The ideal gas model is adopted for water vapour included in the system anulus;

- Pure conduction heat transfer is considered in the water in the storage tank.

The thermal network modelled in the developed simulation tool is presented in Figure 3. The thermal nodes correspond to the following temperatures $(T)$ and thermal capacities $(C)$ :

- $T_{a m b}$, referred to the ambient air;

- $T_{\text {sky }}$, referred to the sky volt;

- $T_{1}$ and $T_{1}^{\prime}$, referred to the external and internal glass cover surfaces, respectively;

- $T_{2}$ and $T_{2}^{\prime}$, referred to the external and internal outer cylinder surfaces, respectively;

- $T_{3}$ and $T_{3}^{\prime}$, referred to the external and internal inner cylinder surfaces, respectively;

- $T_{w}$ and $C_{w}$, referred to the tank water (here, no stratification phenomena are considered);

- $T_{e c}$, referred to the PVC endcaps of the cylinder bases.

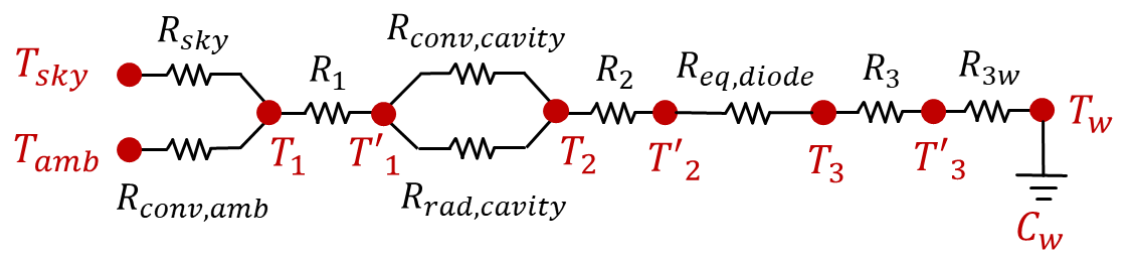

Figure 3. Modelled thermal network.

Different thermal resistances are taken into consideration in the modelled thermal network. Specifically, in Figure 3:

- $R_{s k y}$ is the radiative thermal resistance between the glass cover and the sky volt or between the endcaps and the sky volt;

- $R_{\text {conv, amb }}$ is the convective thermal resistance between the glass cover cylinder and the ambient air or between the endcaps and the ambient air;

- $R_{1}$ is the thermal resistance of the glass cover;

- $\quad R_{\text {conv,cavity }}$ and $R_{\text {rad,cavity }}$ are the convective and radiative thermal resistances between the glass 
cover and the outer system cylinder, respectively;

- $R_{2}$ is the conductive thermal resistance of the outer cylinder;

- $R_{\text {eq,diode }}$ is the resulting thermal resistance describing the diode behaviour which takes into account the heat transfer fluid (HTF) evaporation and condensation effects, along with radiative and convective phenomena. This resistance is differently assessed in case of forward $\left(R_{\text {eq,diode,forward }}\right)$ and reverse $\left(R_{\text {eq,diode,reverse }}\right)$ operating conditions, both described in the following;

- $R_{3}$ is the conductive thermal resistance of the inner cylinder;

- $R_{3 w}$ is the thermal resistance between the inner cylinder and the water inside the storage tank,

In the following, only the $R_{\text {eq,diode }}$ model (related to the occurring phenomena between $T_{2}^{\prime}$ and $T_{3}$, Figure 3) is described in detail (since all the rest are referred to well-known heat transfer behaviours) for sake of brevity (all the other resistances are described in the Appendix). Forward and reverse operational modes of the thermal diode are separately analysed. According to the thermodynamic behaviour of the HTF, in the system annulus, during forward mode, the internal surface of the outer cylinder is described and termed as the evaporator whilst the external surface of the inner cylinder is termed the condenser.

\section{Forward mode}

During thermal diode forward mode operations, in which heat obtained through the available solar radiation is stored in the inner storage tank (out-to-in heat flux direction), the following heat transfer phenomena occur between the SolaCatcher outer and inner cylinder:

- water evaporation from the outer cylinder internal surface;

- subsequent condensation on the inner cylinder external surface;

- radiation between the inner and outer cylinder surfaces.

In the developed simulation tool, the occurring evaporation and condensation phenomena are described by two thermal resistances ( $R_{e}$ and $R_{c}$, respectively) whose overall heat transfer phenomena is described by a suitable equivalent thermal resistance - $R_{\text {eq,diodeforward, }}$ as shown in the thermal sub-networks presented in Figure 4. 


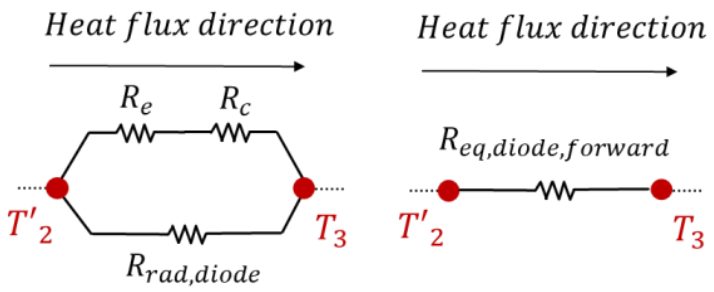

Figure 4. System thermal sub-networks including the thermal diode in the forward mode

$R_{e}=\frac{R_{\text {vap }} \cdot T_{S, \text { outer }, \text { in }}^{2} \cdot \sqrt{2 \cdot \pi \cdot R_{\text {vap }} \cdot T_{S, \text { outer }, \text { in }}}}{A_{\text {outer }, \text { in }} \cdot Q_{L}{ }^{2}\left(T_{S, \text { outer }, \text { in }}\right) \cdot P\left(T_{S, \text { outer }, \text { in }}\right)}$

$$
R_{c}=\frac{R_{\text {vap }} \cdot T_{S, \text { inner }, \text { ext }}^{2} \cdot \sqrt{2 \cdot \pi \cdot R_{\text {vap }} \cdot T_{S, \text { inner }, \text { ext }}}}{A_{\text {inner }, \text { ext }} \cdot Q_{L}{ }^{2}\left(T_{S, \text { inner }, \text { ext }}\right) \cdot P\left(T_{S, \text { inner }, \text { ext }}\right)}
$$

where: $A_{\text {outer, in }}$ and $A_{\text {inner,ext }}$ are the internal surface of the outer cylinder and external surface of the inner cylinder, respectively. $R_{\text {vap }}$ is the water vapour gas constant; $T_{s}$ is the temperature of the considered surface; and $Q_{L}$ and $P$ are the water latent heat of evaporation/condensation and the water vapour pressure, respectively (both assessed at $T_{s}$ temperature).

With respect to Figure 4 , the radiative resistance between the absorber and the condenser $\left(R_{\text {rad,diode }}\right)$ is assessed by applying the following correlation for radiative heat transfer between concentric

$$
R_{\text {rad }, \text { diode }}=\left(\frac{\sigma \cdot\left(T_{\text {outer }, \text { in }}^{2}+T_{\text {inner }, \text { ext }}^{2}\right) \cdot\left(T_{\text {outer }, \text { in }}+T_{\text {inner }, \text { ext }}\right)}{\frac{1-\varepsilon_{\text {outer }, \text { in }}}{\varepsilon_{\text {outer }, \text { in }} \cdot A_{\text {outer }, \text { in }}}+\frac{1}{F_{\text {inlout }} \cdot A_{\text {inner }, \text { in }}}+\frac{\left(1-\varepsilon_{\text {inner }, \text { ext }}\right)}{\varepsilon_{\text {inner }, \text { ext }} \cdot A_{\text {inner }, \text { in }}}}\right)^{-1}
$$

where: $\sigma$ is the Stefan boltzmann constant, $\varepsilon_{\text {outer,in }}$ and $\varepsilon_{\text {inner,ext }}$ are emissivities of the considered surfaces; and $F_{\text {in/out }}$ is the view factor between inner and outer cylinders (in this case $F_{\text {in/out }}=1$ ).

In forward mode, the resulting equivalent thermal resistance of the system diode is: 


$$
R_{e q, \text { diode, forward }}=\left(\frac{1}{\left(R_{e}+R_{c}\right)}+\frac{1}{R_{\text {rad, diode }}}\right)^{-1}
$$

250

\section{Reverse mode}

During thermal diode reverse mode operation, in which no/weak solar radiation occurs and ambient temperatures fall below the tank storage water temperatures, thermal loss is minimised (in-to-out heat flux direction) and so the following heat transfer phenomena occurs in the SolaCatcher system. Initially, evaporation and condensation occur in a reverse direction process with respect to the collection mode: evaporation on the external surface of the inner cylinder and the condensation on the internal surface of the outer cylinder. This undesired phenomenon, due to the residual liquid water film previously condensed on the inner cylinder during the forward mode, relates to an initial storage heat loss to ambient. Note that, during this time, the presented diode equations describing the forward mode are still valid to assess the reverse mode. When the above-mentioned liquid film is completely evaporated, no more evaporation and condensation will occur. Thereafter, the following heat transfer phenomena take place between the outer and inner cylinders:

- convection in the low pressure water vapour atmosphere of the anulus between the inner and outer cylinder surfaces (according to the considered boundary conditions, the system behaviour is approached as a pure conductive phenomenon);

- radiation between the inner and outer cylinder surfaces.

In the developed simulation tool, such phenomena are described by two thermal resistances ( $R_{\text {conv,diode }}$ and $R_{\text {rad,diode, }}$ respectively) whose overall heat transfer phenomena is described by a suitable equivalent thermal resistance - $R_{\text {eq,diode,reverse }}$, as shown in the thermal sub-networks reported in Figure 5.

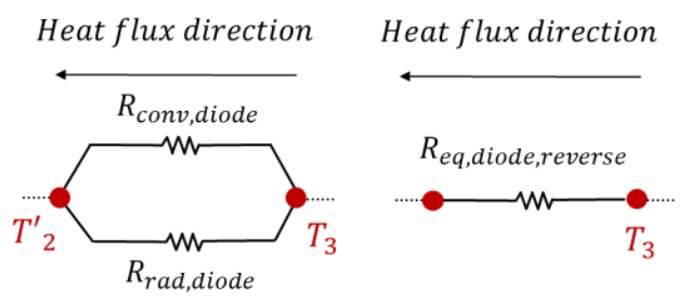


In the developed simulation model $R_{\text {conv,diode }} \equiv R_{\text {cond,diode }}$ and is assessed by suitable experimental 279 correlation [26]:

$$
R_{\text {conv, diode }} \equiv R_{\text {cond, diode }}=\frac{\ln \left(D_{\text {outer,in }} / D_{\text {inner }, \text { ext }}\right)}{2 \cdot \pi \cdot k_{\text {eff }, \text { vap }} \cdot L_{\text {coll }}}
$$

282

$$
k_{\text {eff }, \text { vap }}=\frac{k_{\text {vap }}}{1+\frac{2 \cdot\left(9 \cdot c_{p} / c_{v}-5\right) \cdot \lambda}{\left(c_{p} / c_{v}+1\right) \cdot \ln \left(D_{\text {outer, }, \text { }} / D_{\text {inner }, \text { ext }}\right)}\left(\frac{1}{D_{\text {outer }, \text { in }}}+\frac{1}{D_{\text {inner }, \text { ext }}}\right)}
$$

where: $c_{p}$ and $c_{v}$ is the specific heat of water vapour at constant pressure and volume, respectively; $k_{\text {vap }}$ represents the water vapour thermal conductivity; and $\lambda$ is the mean free path of the water

$$
\lambda=\frac{K \cdot T_{\text {vap }}}{\sqrt{2} \cdot \pi \cdot P_{\text {vap }} \cdot \delta^{2}}
$$

where: $K$ is the Boltzmann constant $\left(1.381 \times 10^{-23} \mathrm{~J} / \mathrm{K}\right) ; P_{\text {vap }}$ is water vapour pressure; $\delta$ is the water molecular diameter $\left(2 \mathrm{e}^{-10} \mathrm{~m}\right)$; and $T_{\text {vap }}$ is the water vapour temperature (computed at a mean temperature between $T_{2}^{\prime}$ and $T_{3}$ ).

The radiative thermal resistance $\left(R_{\text {rad,diode }}\right.$, Figure 5$)$ is assessed by means of the same equation adopted in case of forward mode (Eq. 6). Finally, the resulting thermal diode equivalent resistance in the reverse mode is calculated as:

$$
R_{\text {eq, diode, reverse }}=\left(\frac{1}{R_{\text {conv, diode }}}+\frac{1}{R_{\text {rad, diode }}}\right)^{-1}
$$

\section{Overall system performance}

By iteratively solving the equations set based on the thermal network depicted in Figure 3, all the investigated system temperatures are calculated. As an example, the tank water temperature is 


$$
M_{w} \cdot c_{p w}\left[T_{w}(\theta)-T_{w}(\theta-1)\right]=\frac{T_{3}^{\prime}(\theta)-T_{w}(\theta)}{R_{3, w}} \Delta \theta
$$

where: $M_{w}$ and $c_{p w}$ are the mass and the water specific heat of the liquid water; $T_{w}(\theta)$ and $T_{w}(\theta-1)$ represent the water temperatures inside the tank at the current and previous timestep, respectively; and $\Delta \theta=(\theta)-(\theta-1)$ is the simulation timestep length. For the remaining system nodes similar energy balances are implemented in the developed model for assessing the related temperatures.

The thermal energy variation of the water tank, $\Delta Q_{w}$ (useful collected heat and heat losses for forward and reverse modes, respectively) is assessed in any time interval by $T_{w}(\theta)$ obtained by equation (10). $\Delta Q_{w}$ is respectively calculated as:

$$
\Delta Q_{w, \text { forward }}=\sum_{\theta=1}^{N} M_{w} \cdot c_{p, w} \cdot\left[T_{w}(\theta)-T_{w}(\theta-1)\right]
$$

$$
\Delta Q_{w, \text { reverse }}=\sum_{\theta=N}^{M} M_{w} \cdot c_{p, w} \cdot\left[T_{w}(\theta)-T_{w}(\theta-1)\right]
$$

where: $N$ and $M$ are referred to the time end of the forward and reverse modes, respectively.

The thermal energy collection efficiency $\left(\eta_{\text {forward }}\right)$ is calculated as:

$\eta_{\text {forward }}=\left(\frac{\Delta Q_{w, \text { forward }}}{Q_{\text {sol.incident }}}\right) \cdot 100=\left\{\frac{M_{w} \cdot c_{p, w} \cdot\left[T_{w}(\theta)-T_{w}(\theta-1)\right]}{\sum_{\theta=1}^{N} G \cdot A_{a b s}}\right\} \cdot 100$

327 where: $Q_{\text {sol, incident }}$ is the solar energy incident onto the collector absorber; $G$ is the incident solar 328 radiation; and $A_{a b s}$ is the collector absorber surface.

329 The stored energy efficiency during the reverse mode time is presented as: 330

$331 \quad \eta_{\text {reverse }}=1-\frac{T_{w}(N)-T_{w}(M)}{T_{w}(N)-T_{\text {amb }}(M)}$ 
333 where: $T_{w}(N)$ represents the water tank temperature at the end of the forward mode period; and $334 T_{w}(M)$ and $T_{a m b}(M)$ represent the water tank and the ambient air temperatures at the end of the 335 reverse mode period, respectively.

\section{Dynamic simulation tool}

338

In order to dynamically assess the presented prototype performance, the described mathematical model was implemented in MatLab environment. The resulting dynamic simulation tool is capable to predict the SolaCatcher thermal behaviour under different boundary and operating conditions. In order to show the software logic, in Figure 6 a flow chart reporting the main simulation steps is presented. From the figure it is possible to see that, for each timestep $(\theta)$, the boundary and initial conditions are respectively brought from the weather data file and from the previous timestep $(\theta-1)$. Then, the calculation procedure is iteratively carried out until the error is lower than a selected value (err $<10^{-6}$ ) obtaining the new variables values for the considered simulated timestep $(\theta)$. The simulation is completed when the last timestep $\left(\theta_{\text {end }}\right)$ is evaluated.

\section{Experimental setup description}

The horizontal SolaCatcher prototype (shown in Figure 2) was experimentally evaluated using the state-of-the-art indoor Solar Simulator facility at the Centre for Sustainable Technologies (CST) of Ulster University [28]. The indoor solar simulator testing facility consists of 35 high power metal halide lamps arranged in 7 rows of 5 lamps. Each lamp is equipped with a rotational symmetrical paraboloidal reflector that provides a light beam of high collimation. In order to achieve uniform distribution of light intensity on the test area, a lens is inserted into each lamp to widen the illumination of light. The combination of reflector-characteristics, lens and lamps ensures a realistic simulation of the beam path, spectrum and uniformity. The solar simulator control panel maintained the constant level light intensity automatically on the collector surface via a pyranometer mounted at the centre of the test plane. Figure 7 shows the experimental setup and prototype under test. Indoor solar thermal simulator testing provided consistent/repeatable test conditions as well as instantaneous and average collection efficiencies over a 6 hour period. Heat loss coefficients and heat retention efficiencies are achieved from overnight cool-down period testing. 


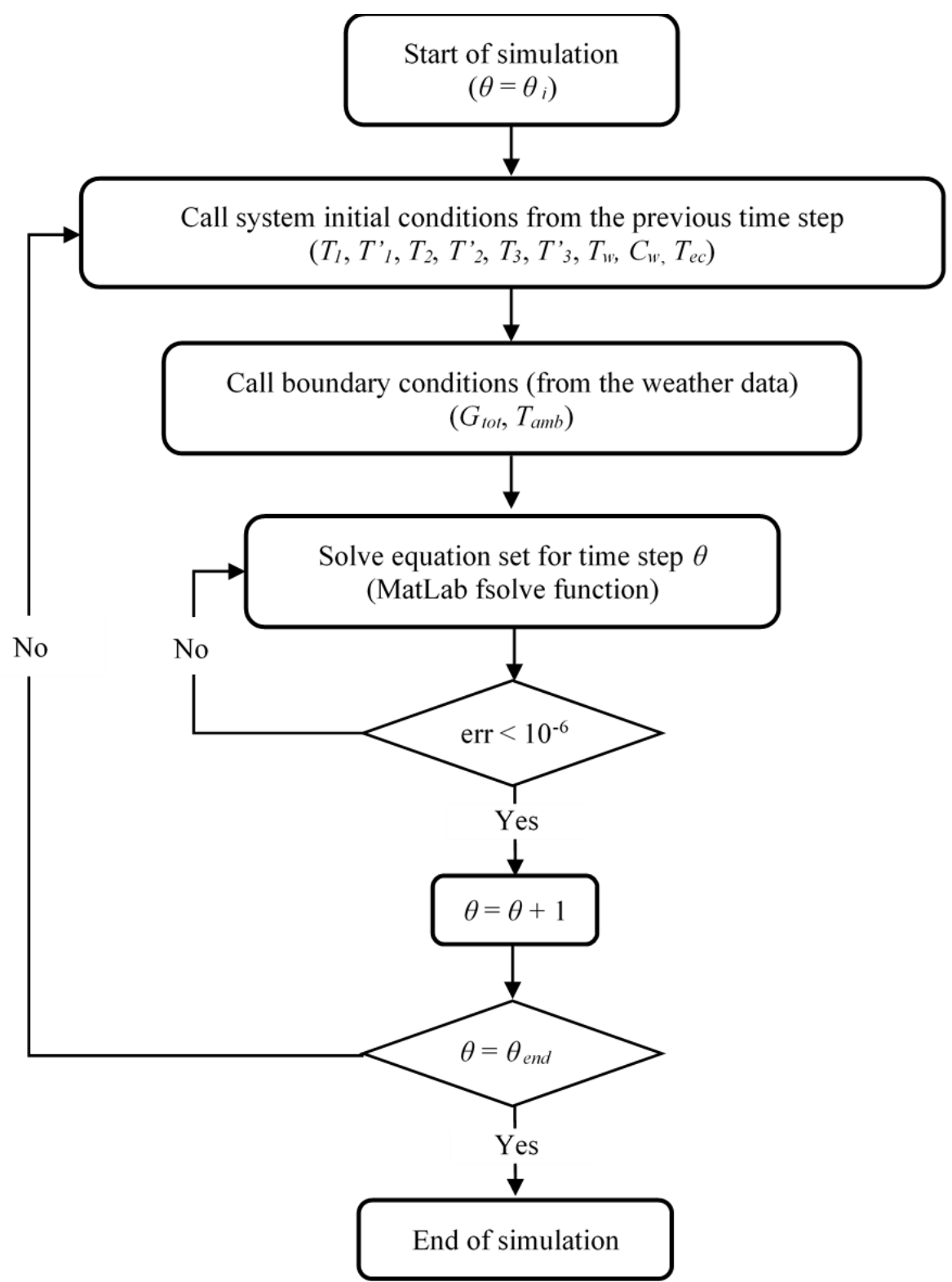

Figure 6. Calculation procedure block diagram. 


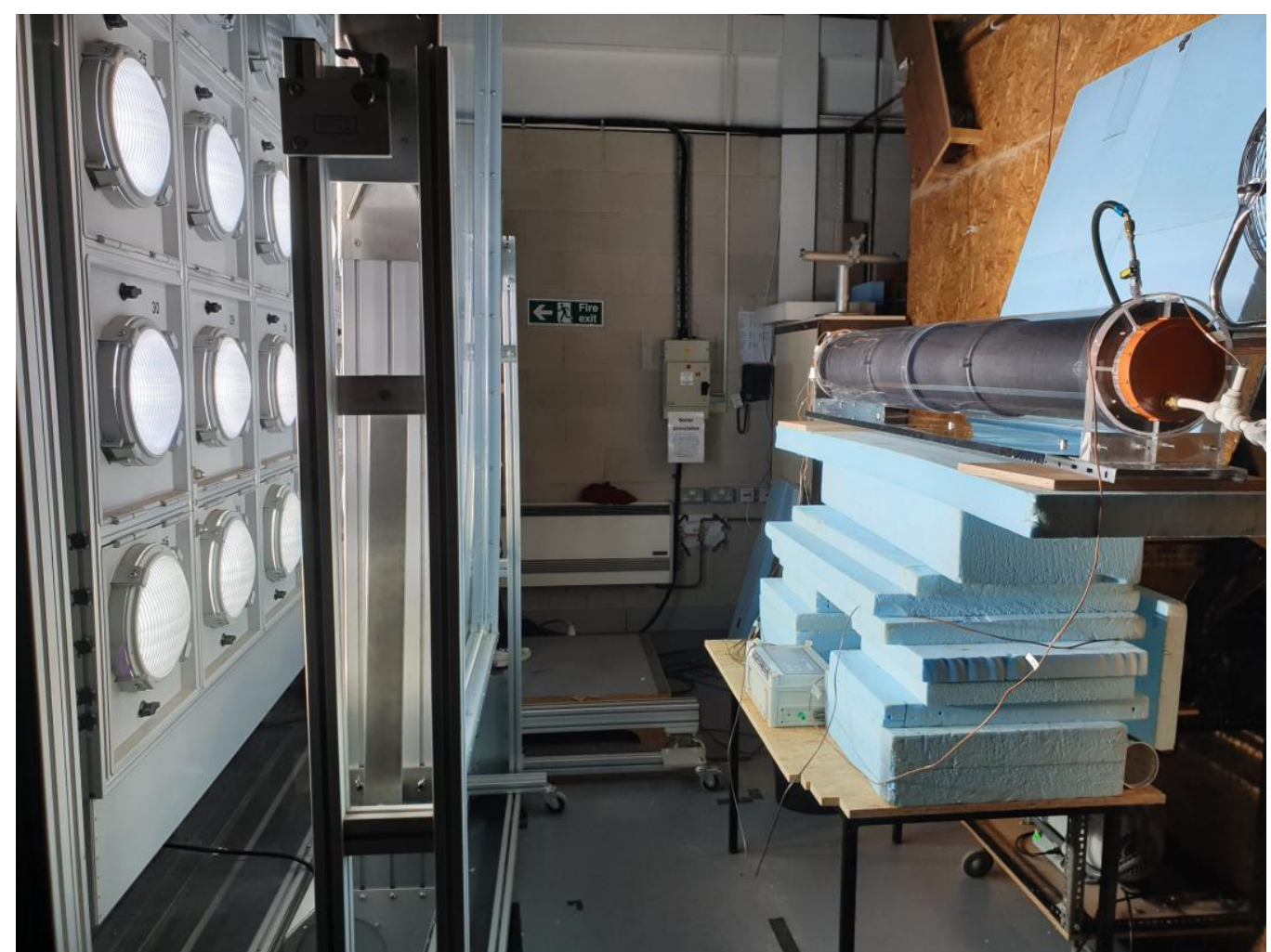

Figure 7. Indoor solar thermal simulator experimental setup and testing.

Figure 8 depicts a cross sectional diagram of the examined prototype. Using suitable T-type copper/constantan thermocouples (accuracy $\pm 0.5 \mathrm{~K}$ ), measurements of ambient air temperatures, vessel surfaces and water $\left(T_{a m b} \equiv T_{s k y}, T_{1}, T_{2}, T_{3}\right.$ and $\left.T_{4}\right)$ were taken. A purpose made test rig was created to mount the horizontal SolaCatcher to permit experimental analysis. Radiation from the solar simulator is set at an incidence angle of $90^{\circ}$ with respect to the vertical system plane as shown in Figure 7. For each test a radiation of $715 \pm 10 \mathrm{~W} / \mathrm{m}^{2}$ was measured on the prototype glass cover surface in order to simulate typical average solar radiation conditions incident on a device located on a building roof over a 6 hour period between 10 a.m. to 4 p.m. in equatorial zones [29]. Incident radiation levels on each SolaCatcher aperture were measured through an integrated pyranometer (Kipp \& Zonen CM4) with a sensitivity $6.87 \mu \mathrm{VW} / \mathrm{m}^{2}$. The annulus pressures were measured through a digital pressure gauge (Druck DPI104-1) with $0.05 \%$ full-scale accuracy. Experimental measurements were recorded under no draw-off conditions for 24 hours. Typically, 6 to 8 hours of simulator radiation collection and 16 to 18 hours of cool-down (heat retention). 


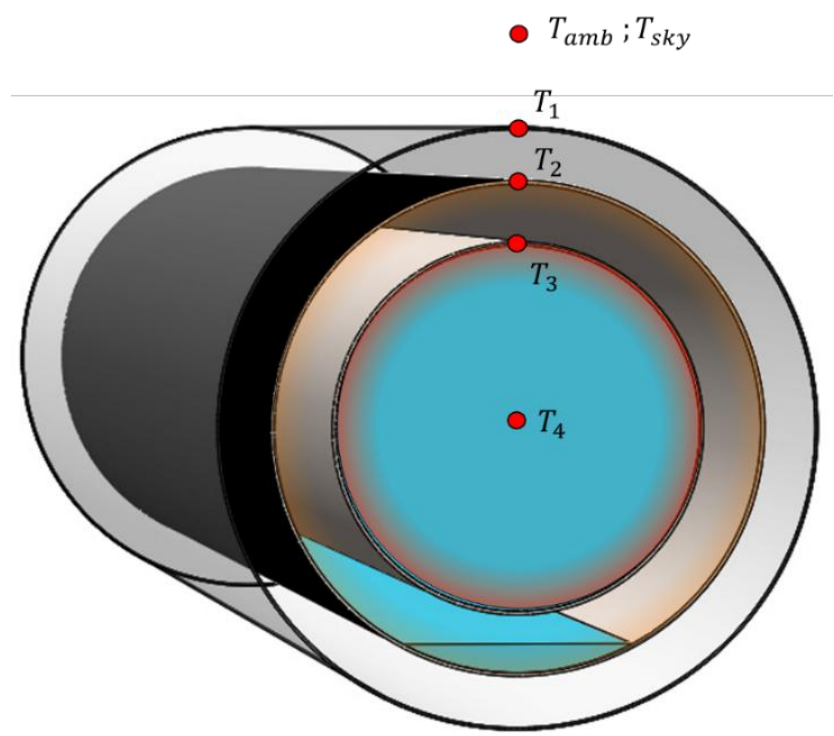

Figure 8. Cross section of the SolaCatcher ICS solar collector.

\section{Experimental results}

A number of experimental tests were conducted on the SolaCatcher prototype through the abovementioned solar simulator facility. Through the obtained test results, the performance of the SolaCatcher under different operating conditions (with and without glass thermal insulation cover and different: radiation levels; storage volumes; and annulus pressures) was assessed.

Results are shown in Figure 9 reporting, for a suitable single test, the recorded time history of the investigated prototype temperatures: $T_{1}, T_{2}, T_{3}, T_{4}$ and $T_{a m b} \equiv T_{s k y}$. Experimental measurements obtained during all conducted tests were used in validating the developed simulation mathematical model, previously shown. Additional testing was conducted to determine the performance characteristics of the unit, although it is not the focus of this paper some of the key performance indicators are presented. Further experimental information will be presented in a follow up publication.

With regard to the results presented in Figure 9 , the collection and retention efficiencies $\left(\eta_{\text {forward }}\right.$ and $\eta_{\text {reverse }}$, respectively) can be respectively evaluated with the already shown Equation 12 and Equation 13, by taking into account the entire forward and reverse period. Concerning the collector's thermal losses, $U_{s}$, during the overnight heat loss period, Equation 14 is the data reduction model to estimate the coefficient of water storage thermal losses assumes an idealised exponential temperature decay. 
$U_{s}=\frac{M_{w} \cdot c_{p w}}{\Delta \theta} \cdot \ln \left[\left(T_{w}(N)-T_{a m b, a v g}\right) /\left(T_{w}(M)-T_{a m b, a v g}\right)\right]$

412

413

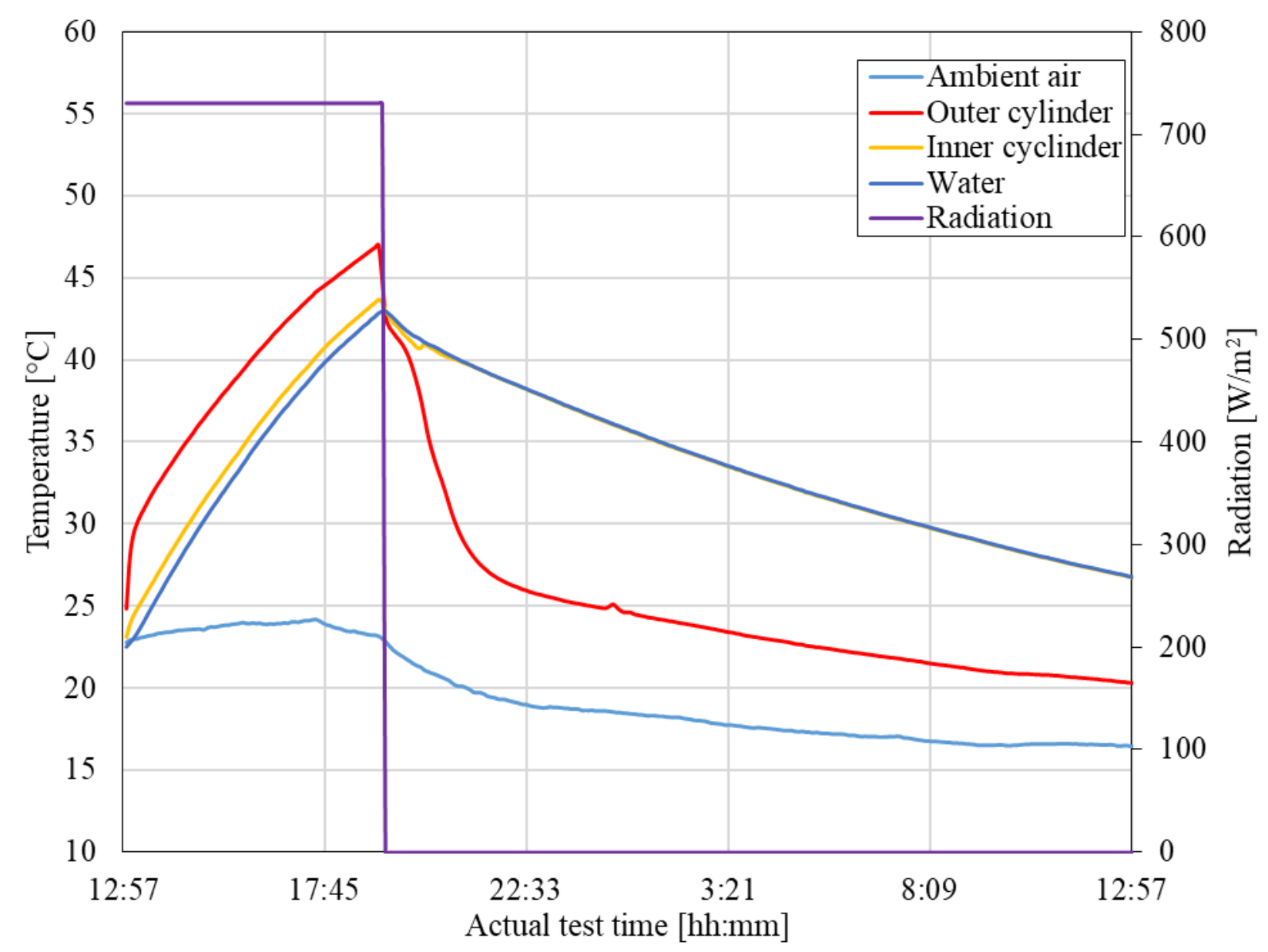

where all the terms are known with exception to $T_{a m b, a v g}$ representing the average ambient air temperature over the time interval of the considered heat loss period.

Figure 9. Measured temperature profile for components in the SolaCatcher (under $715 \pm 10 \mathrm{~W} / \mathrm{m}^{2}$ solar simulated radiation during the $6 \mathrm{hr}$ collection period)

The unit used in the validation process had an average mean collection efficiency ( $\eta_{\text {forward }}$ ) of 54\% with the adapted collection efficiency curve presented in Figure 10. The thermal heat retention efficiency $\left(\eta_{\text {reverse }}\right)$ of the unit after a 12 hour cooldown period was $52 \%$ with a corresponding system thermal loss coefficient $\left(U_{s}\right)$ of $1.93(\mathrm{~W} / \mathrm{K})$. The values presented herein are somewhat lower than those measured in follow on work, where lessons learnt have been deployed in optimised designs. The primary reasons being poor quality of the transparent cover, a lower thermal diode quality and the limited insulation on the end caps. 


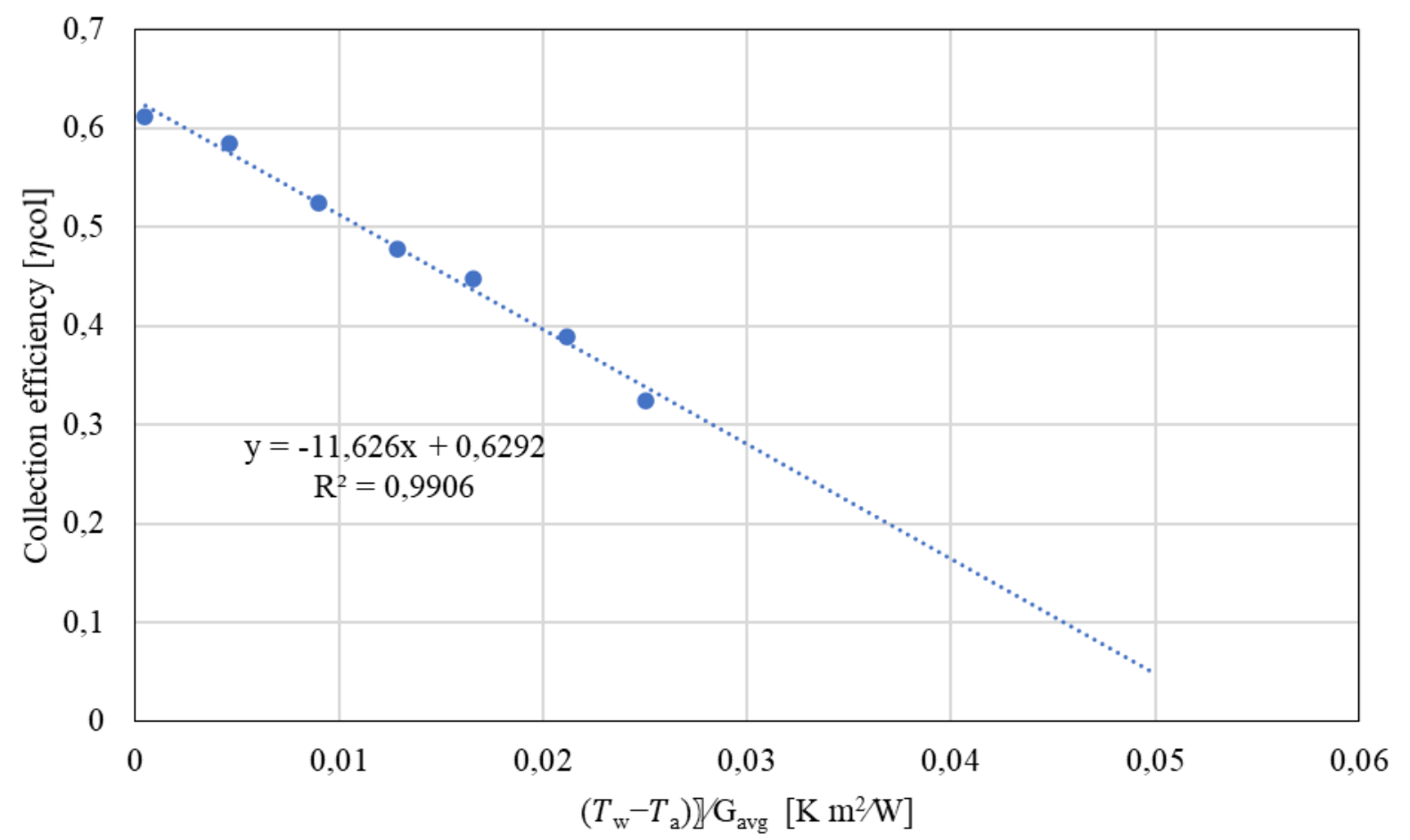

Figure 10. Collection efficiency 'curve' for the SolaCatcher (under $715 \pm 10 \mathrm{~W} / \mathrm{m}^{2}$ solar simulated radiation during the $6 \mathrm{hr}$ collection period)

\section{Model validation}

The previously described mathematical model, implemented in MatLab environment, was validated for both forward and reverse operating modes by means of the experimental data gathered during the previously described empirical analysis. Note that three are the main temperatures considered for the validation: i) outer cylinder temperature; ii) inner cylinder temperature; iii) tank water temperature. The accuracy of the simulated tank water temperature is essential to correctly assess the energy performance of the considered prototype whereas the cylinder values are crucial to properly simulate the thermal diode behaviour (evaporation and condensation phenomena). In order to verify the software accuracy, the validation procedure is carried out for a full one-day cycle (24 hours - see Figure 9) of heat collection and retention. To perform the validation, a suitable climatic data file made from the experimental testing conditions (air temperature, incident radiation from solar simulator, etc.) has been developed. The temperature data obtained from the simulation have then been compared to those gathered during the experimental program. The results of the simulation and experimental analysis are reported in Figure 11, Figure 12 and Figure 13, respectively (here, a suitable accuracy band of $1{ }^{\circ} \mathrm{C}$ is assumed, in accordance to the thermocouples accuracy). The time histories of the outer and inner cylinder temperatures as well as the tank water temperatures are reported. In the same figures the deviation (in absolute values) of the simulated temperature vs. experimental temperature are also shown. Note that the shown experimental values 
are obtained with an incident radiation, from the solar simulator, equal to $715 \pm 10 \mathrm{~W} / \mathrm{m}^{2}$.

By observing all the temperature profiles, a good agreement between the dynamic simulation model outputs and the experimental data is apparent. Specifically, all the simulated temperature deviation, with respect to the corresponding experimental measurements are within an error band of $\pm 1^{\circ} \mathrm{C}$. In particular, a very good agreement between simulated and experimental results is achieved for the tank water temperature, as shown in Figure 13 (the maximum deviations are $\sim \pm 0.5^{\circ} \mathrm{C}$ ). The only exception is the outer cylinder temperatures during the first hour of the reverse mode (Figure 11) and whilst the simulated vs. experimental temperature deviations are higher, the never exceed $\pm 2^{\circ} \mathrm{C}$. The average percentage error of the simulated vs experimental temperatures for the outer cylinder, inner cylinder and water tank temperatures are $0.92,1.38$ and $1.64 \%$, respectively.

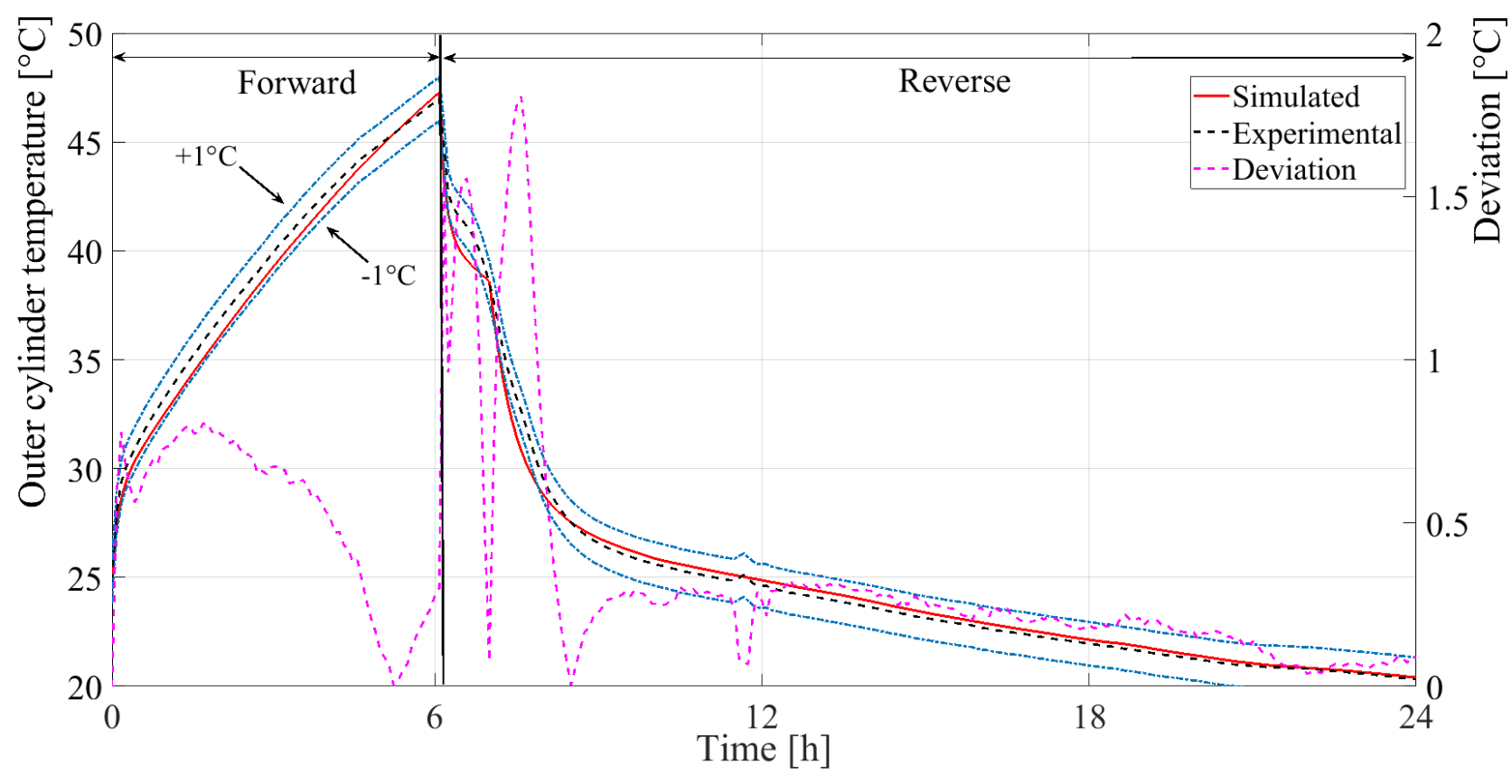

Figure 11. Simulated vs. experimental outer cylinder temperature. 


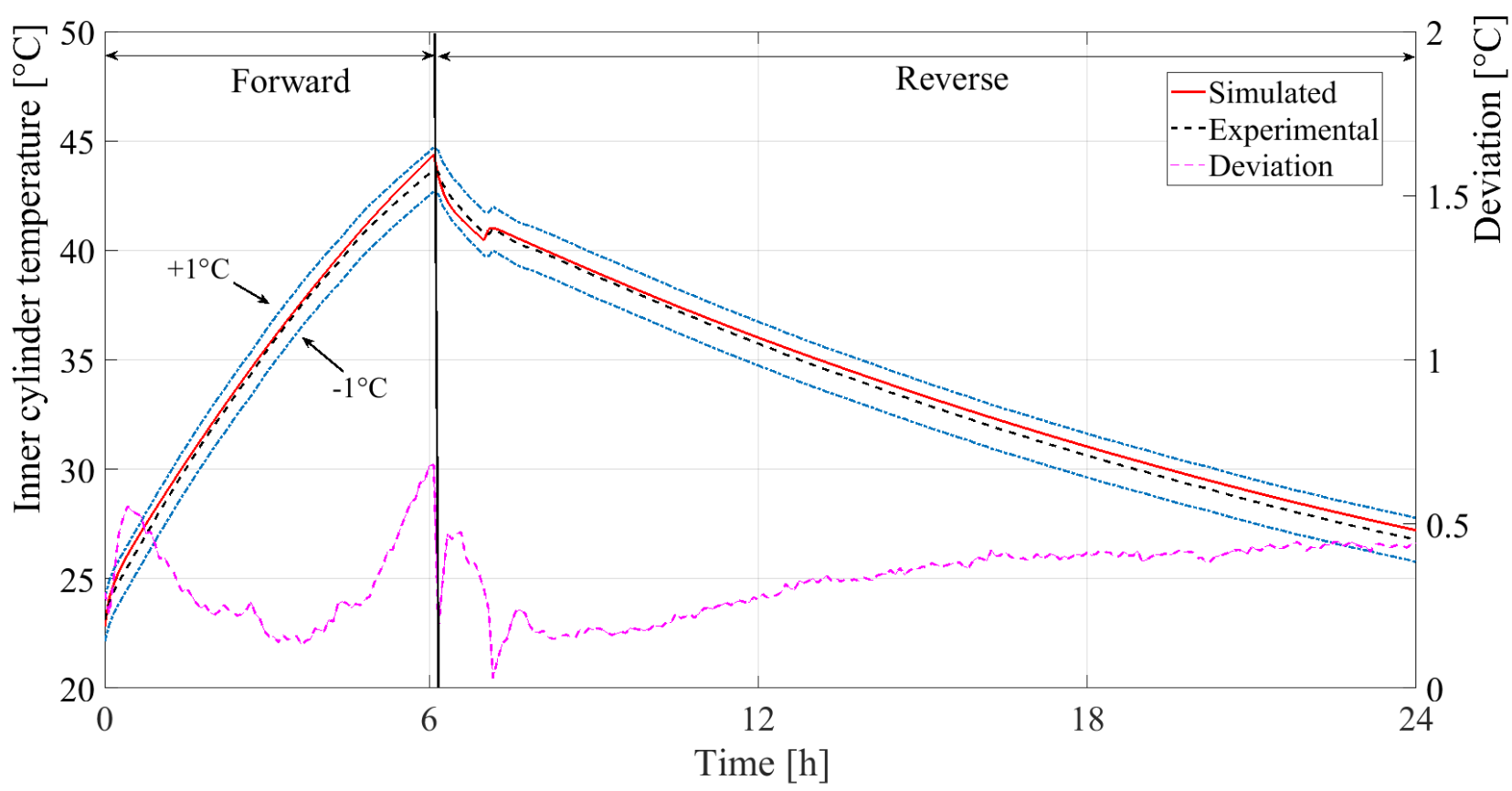

Figure 12. Simulated vs. experimental inner cylinder temperature.

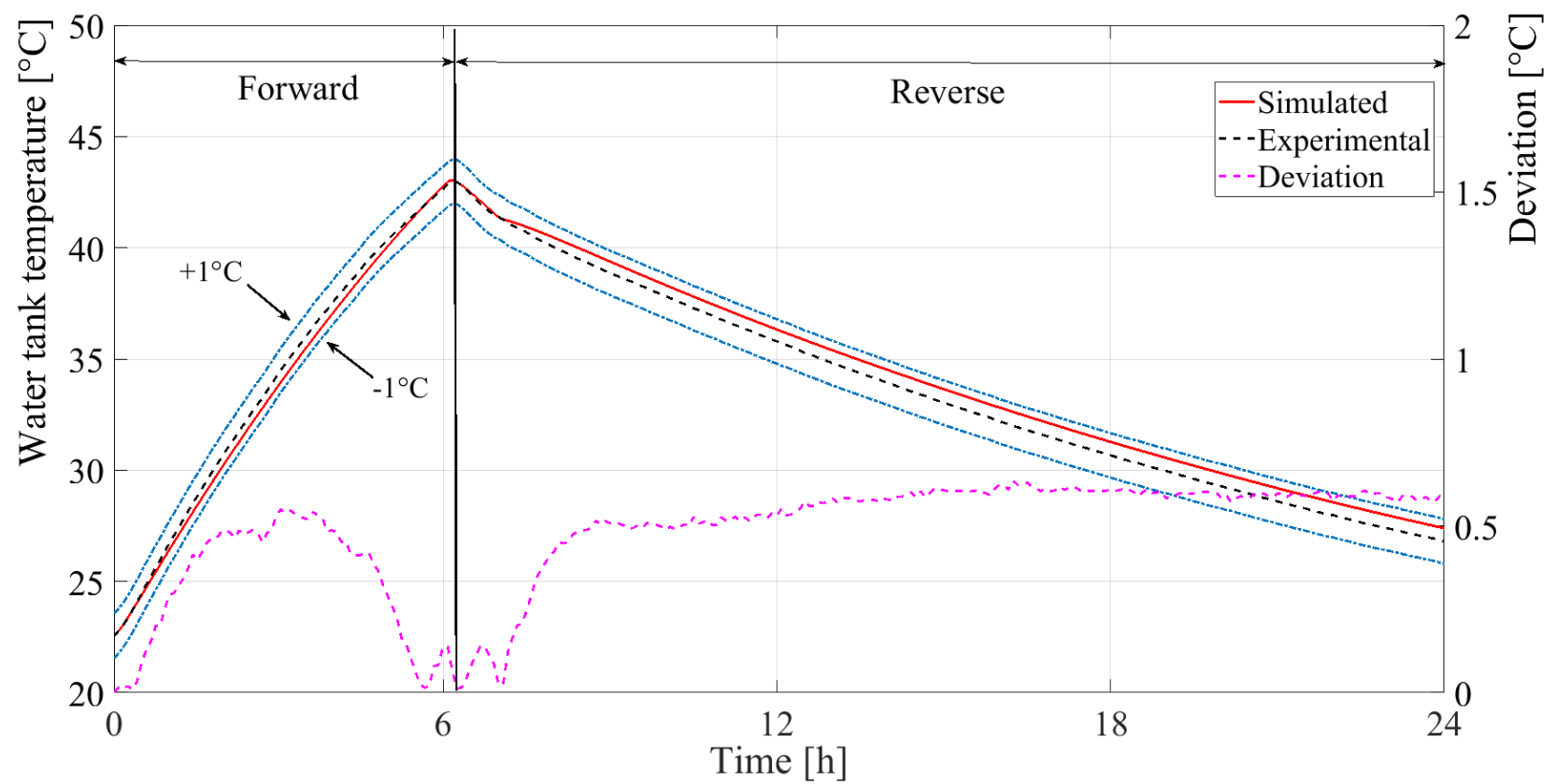

Figure 13. Simulated vs. experimental water tank temperature.

\section{Performance comparison}

In order to prove the optimal energy performance of the SolaCatcher, the related energy performances are compared with those of three geometrically similar devices. Four different system layouts (Figure 14) have been considered in the following analysis:

- Unit 1: the solar collector based on the SolaCatcher thermal diode system. Heat transfer inside the evacuated annulus is obtained by the evaporation/condensation phenomena of a 
working fluid and radiation. A cylindrical glass cover is included.

- Unit 2: the solar collector is conceived with no working fluid (HTF) and no evacuated annulus (the system gap is filled with air at atmospheric pressure). Heat transfer mode inside the annulus is obtained by convection and radiation. A cylindrical glass cover is included.

- Unit 3: the solar collector is conceived with no working fluid (HTF) and by an evacuated annulus. Heat transfer mode inside the annulus is obtained through radiation only. A cylindrical glass cover is included.

- Unit 4: this is the standard basic solar collector featured by a single metallic cylinder as a water storage tank, whose external surface works as the collector absorber. A cylindrical glass cover is included.

All the above described (model) units (1 to 4 ) are identical systems in diameter and length as well as the thermophysical properties are listed in Table 1. By means of the developed simulation tool all these system configurations are modelled and simulated. The obtained results are reported in Figure 15 where the time history of the storage tank water temperatures are reported for a whole sample day. For all the simulations the described boundary conditions (6 simulation hours with $730 \mathrm{~W} / \mathrm{m}^{2}$ of solar radiation and 18 hours without; variable outdoor air temperature as reported in Figure 15) and an initial water temperature $\left(22.5^{\circ} \mathrm{C}\right)$, are considered.
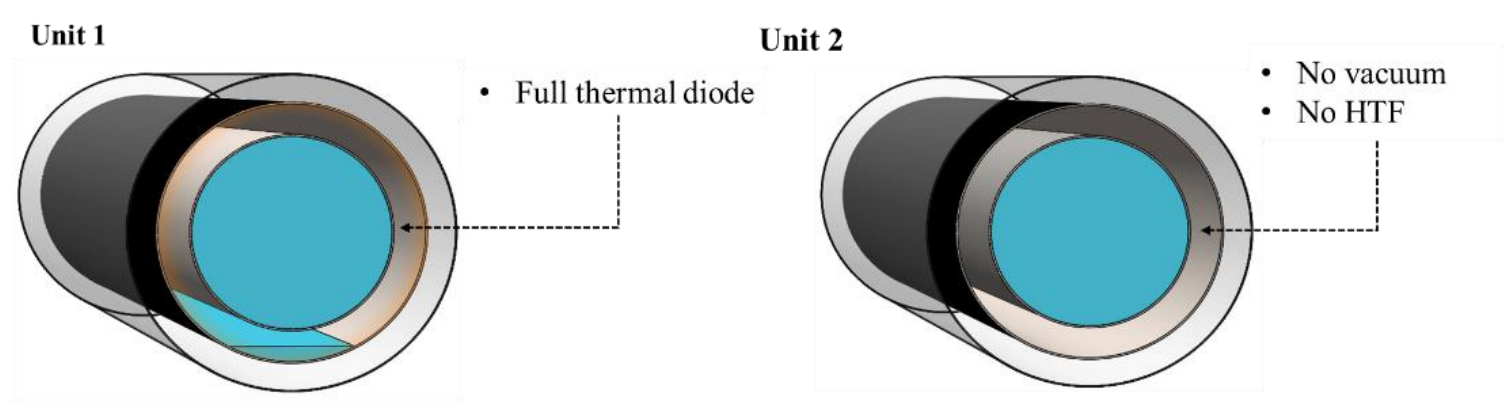

Unit 3

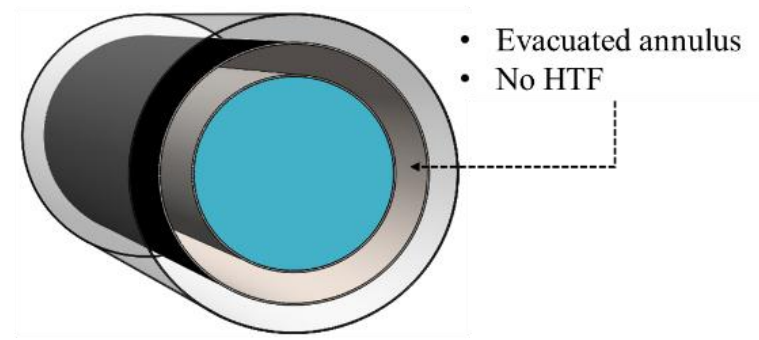

Unit 4

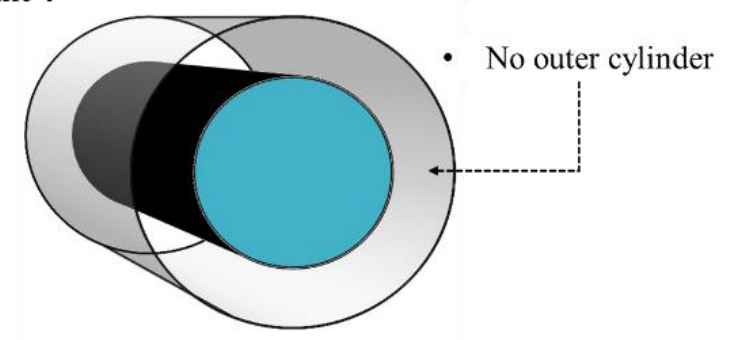




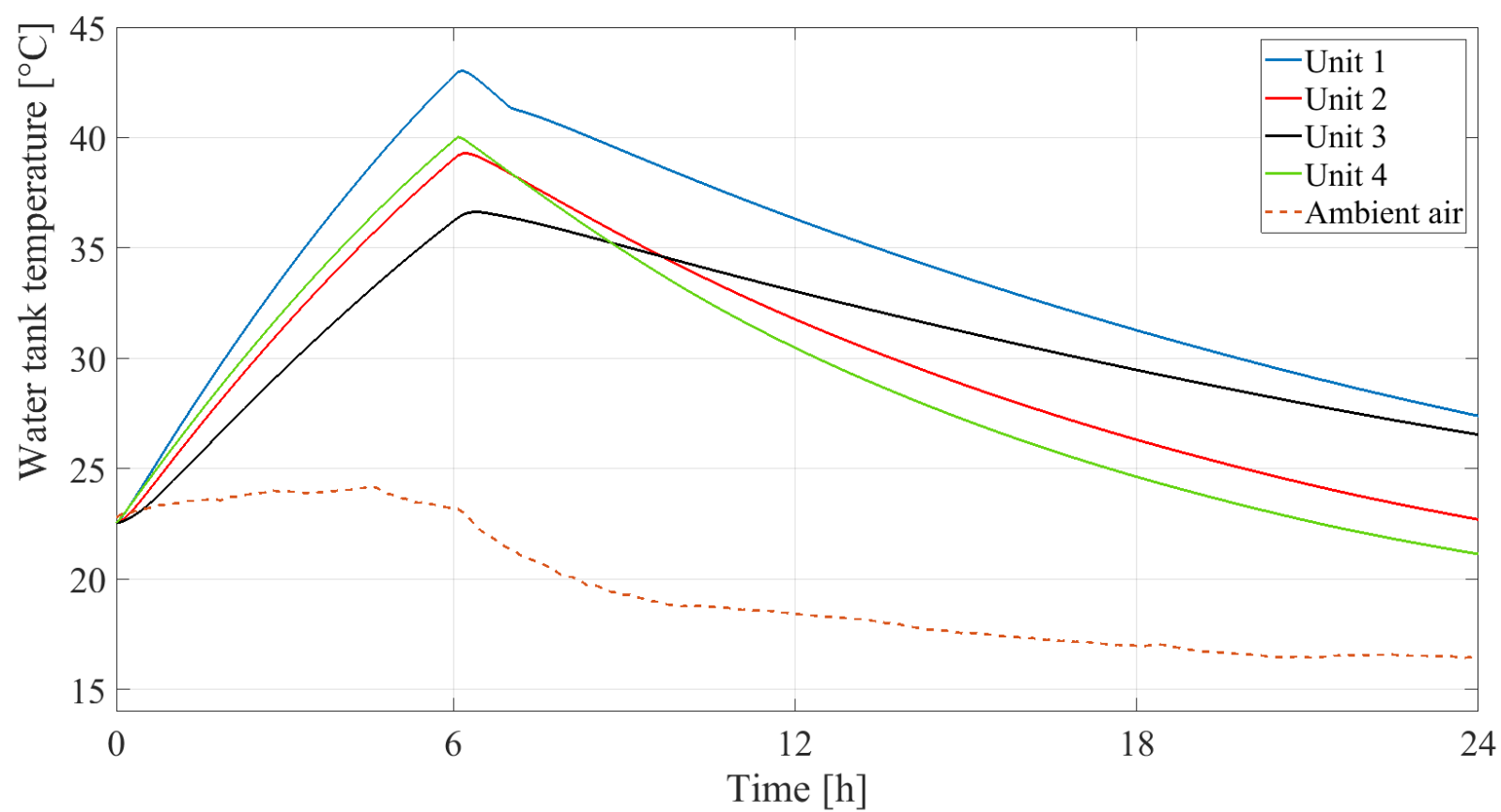

Figure 15. Simulated water storage temperature profiles for different system layouts.

By reviewing Figure 15 the following comments can be stated. The best overall performance in both forward and reverse mode is achieved by the SolaCatcher Unit 1 (blue line). This unit achieved the highest tank water temperature (about $43^{\circ} \mathrm{C}$ after 6 forward mode hours) as well as the lowest heat losses (the minimum water temperature after about 18 reverse mode hours is about $\left.27.5^{\circ} \mathrm{C}\right)$. The thermal energy collection efficiency $\left(\eta_{\text {forward }}\right)$ and the stored energy efficiency $\left(\eta_{\text {reverse }}\right)$ are equal to 54 and $36 \%$, respectively (with 2572 and $1962 \mathrm{~kJ}$ of collected energy and heat losses, respectively).

Unit 2 (red line) exhibits a significantly lower water temperature with respect to Unit 1 in both collection and retention modes. During the forward mode period, the higher annulus thermal resistance (due to the higher resistance given by the convection phenomenon with respect to evaporation/condensation) leads to lower water temperature increase $\left(39^{\circ} \mathrm{C}\right.$ maximum). Conversely, during the reverse mode time, the presence of air inside the annulus increases the system heat losses leading to a remarkable water temperature decrease (around $15^{\circ} \mathrm{C}$ ). The resulting Unit 2 efficiencies ( $\eta_{\text {forward }}$ and $\eta_{\text {reverse }}$ ) are equal to 44 and to $19 \%$, respectively (with 2102 and $2082 \mathrm{~kJ}$ of collected energy and heat losses, respectively).

Similar to Unit 2, Unit 3 (black line) also presents lower water temperatures at the end of both forward and reverse modes with respect to Unit 1. Unit 3 reaches the lowest water temperature at the end of the collection period (about $37^{\circ} \mathrm{C}$ ). This is due to the evacuated annulus and to the 
absence of a working fluid (no convective no and evaporation/condensation phenomena). Thus, the heat transfer inside the annulus in Unit 3 is due to the radiation effect only returning the lowest calculated $\eta_{\text {forward }}(37 \%$, collected energy equal to $1769 \mathrm{~kJ})$. Conversely, the evacuated Unit 3 had the highest $\eta_{\text {reverse }}$, achieving $44 \%$ and energy losses equal to $1266 \mathrm{~kJ}$.

Finally, the collection performance of standard unit, Unit 4, is lower than Unit 1 (the maximum water temperature is about $4^{\circ} \mathrm{C}$ less, with a collected energy of $2196 \mathrm{~kJ}$ ) but higher than Unit 2 and Unit 3. Unit 4 also shows the worst energy retention performance (almost $7^{\circ} \mathrm{C}$ lower than Unit 1 after 18 reverse mode hours, with a heat loss of $2372 \mathrm{~kJ}$ ).

\section{Conclusion}

This paper presents the energy performance analysis of a new Integrated Collector Storage Solar Water Heater (ICSSWH). For this prototype, commercially named the SolaCatcher, designed and built at CST, Ulster University, an in-house one-dimensional dynamic simulation model was developed in MatLab environment. The computer tool was experimentally validated through the empirical data obtained through experimental evaluation in an indoor laboratory solar simulator facility. The tests were carried out under no draw-off conditions for a total period of 24 hours comprising of 6 hours of solar thermal collection and 18 hours of cool-down (heat retention). Simulation results, based on the one-day cycle of heat collection and retention (forward and reverse modes respectively), and referred to the outer cylinder, inner cylinder and tank water temperatures have been compared to the corresponding experimental measurements. A very good agreement between the dynamic simulation model output and the experimental data was achieved, with almost all the modelled temperatures being within $\pm 1^{\circ} \mathrm{C}$ from the respective experimental values. Corresponding average percentage errors of $0.92,1.38$ and $1.64 \%$ for the absorber (outer cylinder), condenser (inner cylinder) and water (storage) temperatures are presented, respectively.

The validated model has been used to predict the water storage temperature profiles for 4 different system layouts, including the considered SolaCatcher. The full thermal diode configuration exhibited the best overall performance in both forward and reverse modes, attaining about $43^{\circ} \mathrm{C}$ at the end of the collection period and around $27.5^{\circ} \mathrm{C} 18$ hours after solar collected ended. Thanks to the developed model, it has been possible to verify the advantages of the SolaCatcher design against the other investigated collector typologies, with similar geometry, characterized by lower performances at the end of the evaluation period. The benefit of the working fluid in the evacuated annulus has been demonstrated, compared to other concentric vessel layouts and significantly better 
than the base case. These results justify the efforts currently being conducted in the prototype optimization.

The developed mathematical model can be used as a comparison tool that can inform the design and development of follow-on SolaCatcher prototypes, under different boundary and working conditions, different weather zones and usage profiles. The results of this investigation will be used to develop new SolaCatcher units for use in the developing world. Optimised physical features and materials will enhance solar collection and heat retention performance whilst cost reductions in fabrication and assembly will improve their economic and environmental potential.

\section{Future perspectives}

In this paper, a dynamic simulation tool capable of predicting the innovative SolaCatcher prototype energy performance is presented along with the adapted mathematical model. By means of the developed tool, it has been possible to verify the prototype convenience over collectors with similar geometry. A continuation study, including a comprehensive parametric analysis will be developed with the aim of finding the design and operating parameters which best improve the performance of the device under diverse boundary and working conditions, e.g. weather zones, load profile, etc..

\section{Acknowledgments}

The work presented in this paper was supported by SolaForm Ltd, the "SolaFin2Go" and "SolaNetwork" projects funded by the UKRI Engineering and Physical Sciences Research Council. The authors would also like to thank networking support funded by the European Union ERASMUS programme.

\section{Appendix}

In this paper, the mathematical model adopted to simulate the SolaCatcher behaviour is presented. For sake of brevity, the discussion covers only the most important heat transfer resistances neglecting the well-known ones. In this Appendix, all the remaining resistances adopted in the mathematical model are presented. By considering the SolaCatcher thermal network presented in Figure 3 , the following parameters, already mentioned before, can be identified: $R_{\text {sky }} ; R_{\text {conv, amb }} ; R_{1}$; $R_{\text {conv,cavity }}, R_{\text {rad,cavity }} ; R_{2} ; R_{\text {eq,diode }} ; R_{3} ; R_{3 w}$. All of these parameters will be specified in the following with the exception of $R_{\text {eq,diode }}$, already explained in Equation 4 and Equation 8 in case of forward and reverse operation mode, respectively.

Starting with $R_{s k y}$, this represents the radiative thermal resistance between the glass cover and the 
598 599 600 601 602 603 604 605

$$
R_{\text {conv }, \text { amb }}=\frac{1}{A_{\text {glass }} \cdot h_{\text {conv }, \text { amb }}}=\frac{D_{\text {glass }, \text { ext }}}{A_{\text {glass }} \cdot N u \cdot k_{\text {air }}}
$$

606

where: $D_{\text {glass,ext }}$ is the glass cover external diameter, $k_{\text {air }}$ is the ambient air thermal conductivity and 607 $\mathrm{Nu}$ is the Nusselt number, estimated as follow:

608

609

$$
N u=\left(0.60+0.387 \cdot\left(\frac{(G r \cdot P r)}{\left(1+(0.599 / P r)^{9 / 16}\right)^{16 / 9}}\right)^{1 / 6}\right)^{2}
$$

610

where $\operatorname{Pr}$ is the Prandtl number and $G r$ is the Grashof number estimated as follows:

612

613

$$
G r=\frac{g \cdot D_{\text {glass }, e x t}{ }^{3} \cdot \beta \cdot\left(T_{1}-T_{a m b}\right)}{v^{2}}
$$

614

where: $\beta$ is the coefficient of thermal expansion (equal to approximately $1 / T$, for ideal gases) and $v$ 617 618 is the kinematic viscosity. The thermal resistances $R_{1}, R_{2}$ and $R_{3}$ are the conductive thermal resistance of the glass cover, outer and inner cylinders respectively. These three resistances can be 619 620

$$
R_{1}=\frac{\ln \left(D_{\text {glass } \text { ext }} / D_{\text {glass, int }}\right)}{2 \cdot \pi \cdot k_{\text {glass }} \cdot L_{\text {coll }}}
$$

$621 \quad R_{2}=\frac{\ln \left(D_{\text {outer, } \mathrm{ext}} / D_{\text {outer, }, \mathrm{int}}\right)}{2 \cdot \pi \cdot k_{\text {outer }} \cdot L_{\text {coll }}}$ 
$622 \quad R_{3}=\frac{\ln \left(D_{\text {inner }, \mathrm{ext}} / D_{\text {inner }, \text { int }}\right)}{2 \cdot \pi \cdot k_{\text {inner }} \cdot L_{\text {coll }}}$

623

624

625

626

627

628

629

630

631

632

$R_{\text {rad }, \text { cavity }}=\left(\frac{\sigma \cdot\left(T_{\text {outer }, \text { ext }}^{2}+T_{\text {glass, in }}^{2}\right) \cdot\left(T_{\text {outer }, \text { ext }}+T_{\text {glass, in }}\right)}{\frac{1-\varepsilon_{\text {outer }, \text { xt }}}{\varepsilon_{\text {outer }, \text { ext }} \cdot A_{\text {outer }, \text { xt }}}+\frac{1}{F_{\text {inlout }} \cdot A_{\text {outer }, \text { ext }}}+\frac{1-\varepsilon_{\text {glass }}}{\varepsilon_{\text {glass }, \text { in }} \cdot A_{\text {glass }, \text { in }}}}\right)^{-1}$ and inner cylinder thermal conductivity coefficient, respectively. follows:
633

$$
R_{\text {conv }, \text { cav }}=\frac{\ln \left(D_{\text {glass }, \text { in }} / D_{\text {outer }, \text { ext }}\right)}{2 \cdot \pi \cdot k_{\text {eq,air }} \cdot L_{\text {coll }}}
$$

where: manner as reported in Equation 3.

where: $D_{\text {glass,ext }}, D_{\text {outer,ext }}$ and $D_{\text {inner, ext }}$ are the glass cover, outer cylinder and inner cylinder external diameters, respectively; $D_{\text {glass,int }}, D_{\text {outer, int }}$ and $D_{\text {inner, int }}$ are the glass cover, outer cylinder and inner cylinder internal diameters, respectively and $k_{\text {glass }}, k_{\text {outer, }}$ and $k_{\text {inner }}$ are the glass cover, outer cylinder

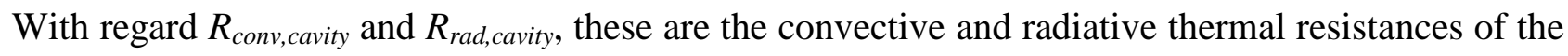
air gap between the outer cylinder and the glass cover. With regard to $R_{\text {rad,cavity }}$, this is expressed as

where: $T_{\text {outer,ext }}$ and $T_{\text {outer,int }}$ are the outer cylinder external and internal surface temperatures, respectively; $T_{\text {glass,ext }}$ and $T_{\text {glass,int }}$ are the glass cover external and internal surface temperatures, respectively; $\varepsilon_{\text {glass,in }}$ and $\varepsilon_{\text {outer,ext }}$ are the emissivity of the internal surface of the glass cover and external surface of the outer cylinder, respectively and $A_{\text {outer,ext }}$ and $A_{\text {glass, in }}$ are the outer cylinder external surface area and the glass cover internal surface area, respectively. Note that $F_{\text {in/out, }}$ which represents the view factor between the outer cylinder and the glass cover, is evaluated in the same

The last parameter to be evaluated is the convective resistance inside the air cavity, $R_{\text {conv,cavity. This }}$ thermal resistance is evaluated by treating the convective heat transfer phenomena as purely conductive by taking into account an air equivalent thermal conductivity $\left(k_{e q, a i r}\right)$ in accordance with Duffie and Beckman [30]. Specifically, the $k_{e q, a i r}$ formulation is: 
651

652 where: $k_{\text {air }}$ is the air thermal conductivity and $G r$ and $\operatorname{Pr}$ are the Grashof and Prandtl numbers.

653 Specifically, the Grashof number can be estimated, similarly to Equation 18, as follows:

654

655

$G r=\frac{g \cdot\left(D_{\text {glass }, \text { in }}-D_{\text {outer }, \text { ext }}\right)^{3} \cdot \beta \cdot\left(T_{1}^{\prime}-T_{2}\right)}{v^{2}}$

656

657 where: $\beta$ is the coefficient of thermal expansion (equal to approximately $1 / T$, for ideal gases) and $v$ 658 is the kinematic viscosity.

659

660 Nomenclature

661

662

663

664

665

666

667

668

669

670

671

672

673

674

\section{Symbols}

A Surface area $\left[\mathrm{m}^{2}\right]$

c $\quad$ Specific heat $[\mathrm{J} / \mathrm{kg} \mathrm{K}]$

C Thermal capacity [J/K]

CST Centre for Sustainable Technologies

D Diameter [m]

F View factor

g gravitational acceleration $\left[\mathrm{m} / \mathrm{s}^{2}\right]$

$\mathrm{G} \quad$ Incident solar radiation $\left[\mathrm{W} / \mathrm{m}^{2}\right]$

Gr Grashof

ICSSWH Integrated Collector Storage Solar Water Heating

$\mathrm{k} \quad$ Thermal conductivity [W/m K]

$675 \mathrm{~h}$

$\mathrm{K} \quad$ Boltzmann constant $[\mathrm{J} / \mathrm{K}]$

676 L

Heat transfer coefficient $\left[\mathrm{W} / \mathrm{m}^{2} \mathrm{~K}\right]$

$677 \mathrm{M}$

Length $[\mathrm{m}]$

$678 \quad \mathrm{~N}$

Mass [kg]; End of reverse mode

$679 \mathrm{Nu}$

$680 \mathrm{P}$

End of forward mode

Nusselt number

681 PCM

Pressure [Pa]

682

$\operatorname{Pr}$

Phase Change Material

$683 \mathrm{Q}$

Prandtl

$684 \mathrm{R}$

Heat [W]

$685 \mathrm{~T}$

Thermal resistance [K/W]; Universal Gas Constant [J/mol K]

Temperature $[\mathrm{K}]$

$686 \mathrm{U}$

System thermal loss coefficient [W/K]

687

688

689

\section{Subscript}

abs

Absorber

$690 \mathrm{amb}$

Ambient air 


$\begin{array}{lll}691 & \text { avg } & \text { Average } \\ 692 & \text { c } & \text { Condensation } \\ 693 & \text { Cavity } & \text { Air cavity } \\ 694 & \text { coll } & \text { Collector } \\ 695 & \text { cond } & \text { Condenser } \\ 696 & \text { conv } & \text { Convective } \\ 697 & \text { e } & \text { Evaporation } \\ 698 & \text { eff } & \text { Effective } \\ 699 & \text { err } & \text { Error } \\ 700 & \text { ext } & \text { External } \\ 701 & \text { eq } & \text { Equivalent } \\ 702 & \text { forward } & \text { Forward mode } \\ 703 & \text { in } & \text { Internal } \\ 704 & \text { ins } & \text { Inside } \\ 705 & \text { L } & \text { Latent } \\ 706 & \text { out } & \text { Outside } \\ 707 & \text { rad } & \text { Radiative } \\ 708 & \text { reverse } & \text { Reverse mode } \\ 709 & \text { s } & \text { Surface } \\ 710 & \text { Sky } & \text { Sky vault } \\ 711 & \text { vap } & \text { Vapour } \\ 712 & \text { W } & \text { Water } \\ 713 & & \\ 714 & \text { Greek } & \\ 715 & \lambda & \text { Molecule mean free path }[\mathrm{m}] \\ 716 & \beta & \text { coefficient of thermal expansion }[1 / \mathrm{K}] \\ 717 & \varepsilon & \text { Emissivity } \\ 718 & \delta & \text { Molecular diameter }[\mathrm{m}] \\ 719 & \sigma & \text { Stephan-Boltzmann constant }\left[\mathrm{W} / \mathrm{m}^{2} \mathrm{~K}^{4}\right] \\ 720 & \eta & \text { Efficiency } \\ 721 & \theta & \text { Timestep } \\ 722 & \Delta \theta & \text { Collection period }[\mathrm{s}] \\ 723 & v & \text { kinematic viscosity }\left[\mathrm{m}^{2} / \mathrm{s}\right] \\ 724 & & \end{array}$

\section{References}

1. Hirst, E., A golden thread: 2500 years of solar architecture and technology: by Ken Butti and John Perlin Cheshire Books, distributed by Van Nostrand Reinhold Company, New York and London, 1980, 304 pp, f11.95. Energy Policy, 1981. 9(2): p. 167.

2. Faiman, D., Towards a standard method for determining the efficiency of integrated collectorstorage solar water heaters. Solar Energy, 1984. 33(5): p. 459-463.

3. Smyth, M., P.C. Eames, and B. Norton, Integrated collector storage solar water heaters. Renewable and Sustainable Energy Reviews, 2006. 10: p. 503-538.

4. Singh, R., I.J. Lazarus, and M. Souliotis, Recent developments in integrated collector storage (ICS) solar water heaters: A review. Renewable and Sustainable Energy Reviews, 2016. 54: p. 270-298.

5. Kalogirou, S., Design, construction, performance evaluation and economic analysis of an integrated collector storage system. Renewable Energy, 1997. 12(2): p. 179-192.

6. Kumar, R. and M.A. Rosen, Thermal performance of integrated collector storage solar water heater with corrugated absorber surface. Applied Thermal Engineering, 2010. 30(13): p. 1764-1768.

7. Kaushik, S.C., R. Kumar, and H.P. Garg, Effect of baffle plate on the performance of a triangular built-in-storage solar water heater. Energy Conversion and Management, 1995. 36(5): p. 337-342. 
8. Cruz, J.M.S., G.P. Hammond, and A.J.P.S. Reis, Thermal performance of a trapezoidal-shaped solar collector/energy store. Applied Energy, 2002. 73(2): p. 195-212.

9. Chaurasia, P.B.L. and J. Twidell, Collector cum storage solar water heaters with and without transparent insulation material. Solar Energy, 2001. 70(5): p. 403-416.

10. Tripanagnostopoulos, Y. and P. Yianoulis, Integrated collector-storage systems with suppressed thermal losses. Solar Energy, 1992. 48(1): p. 31-43.

11. Blanco, M.E., E. Gomez-Leal, and J.M. Gordon, Asymmetric CPC solar collectors with tubular receiver: Geometric characteristics and optimal configurations. Solar Energy, 1986. 37(1): p. 49-54.

12. S. Chatrchyan, V. Khachatryan, A.M. Sirunyan. Measurement of pseudorapidity distributions of charged particles in proton-proton collisions at $V(s)$ \&\#x3D; 8 TeV by the CMS and TOTEM experiments.

13. Souliotis, M., D. Chemisana, Y.G. Caouris, and Y. Tripanagnostopoulos, Experimental study of integrated collector storage solar water heaters. Renewable Energy, 2013. 50: p. 1083-1094.

14. Smyth, M., P. McGarrigle, P.C. Eames, and B. Norton, Experimental comparison of alternative convection suppression arrangements for concentrating integral collector storage solar water heaters. Solar Energy, 2005. 78(2): p. 223-233.

15. Muhumuza, R., A. Zacharopoulos, J.D. Mondol, M. Smyth, and A. Pugsley, Experimental study of heat retention performance of thermal diode Integrated Collector Storage Solar Water Heater (ICSSWH) configurations. Sustainable Energy Technologies and Assessments, 2019. 34: p. 214-219.

16. Souliotis, M., P. Quinlan, M. Smyth, Y. Tripanagnostopoulos, A. Zacharopoulos, M. Ramirez, and P. Yianoulis, Heat retaining integrated collector storage solar water heater with asymmetric CPC reflector. Solar Energy, 2011. 85(10): p. 2474-2487.

17. Souliotis, M., S. Papaefthimiou, Y.G. Caouris, A. Zacharopoulos, P. Quinlan, and M. Smyth, Integrated collector storage solar water heater under partial vacuum. Energy, 2017. 139: p. 9911002.

18. de Beijer, H.A., Product development in solar water heating. Renewable Energy, 1998. 15(1): p. 201204.

19. Smyth, M., P. Quinlan, J.D. Mondol, A. Zacharopoulos, D. McLarnon, and A. Pugsley, The evolutionary thermal performance and development of a novel thermal diode pre-heat solar water heater under simulated heat flux conditions. Renewable Energy, 2017. 113: p. 1160-1167.

20. Smyth, M., P. Quinlan, J.D. Mondol, A. Zacharopoulos, D. McLarnon, and A. Pugsley, The experimental evaluation and improvements of a novel thermal diode pre-heat solar water heater under simulated solar conditions. Renewable Energy, 2018. 121: p. 116-122.

21. Muhumuza, R., A. Zacharopoulos, J.D. Mondol, M. Smyth, A. Pugsley, G.F. Giuzio, and D. Kurmis, Experimental investigation of horizontally operating thermal diode solar water heaters with differing absorber materials under simulated conditions. Renewable Energy, 2019. 138: p. 10511064.

22. Solaform, G.E.E.i.Y.H.w.a.N.G.o.W.T., 2014.

23. Pugsley, A., A. Zacharopoulos, J. Deb Mondol, and M. Smyth, Theoretical and experimental analysis of a horizontal planar Liquid-Vapour Thermal Diode (PLVTD). International Journal of Heat and Mass Transfer, 2019. 144: p. 118660.

24. Boreyko, J., Y. Zhao, and C.-H. Chen, Planar jumping-drop thermal diodes. 2011.

25. Boreyko, J.B. and C.-H. Chen, Vapor chambers with jumping-drop liquid return from superhydrophobic condensers. International Journal of Heat and Mass Transfer, 2013. 61: p. 409418.

26. Ratzel, A.C., C.E. Hickox, and D.K. Gartling, Techniques for Reducing Thermal Conduction and Natural Convection Heat Losses in Annular Receiver Geometries. Journal of Heat Transfer, 1979. 101(1): p. 108-113.

27. Duffie, J.A. and W.A. Beckman, Solar Engineering of Thermal Processes: Fourth Edition. Solar Engineering of Thermal Processes: Fourth Edition. 2013. 